Original Research

\title{
Modulation of Gene Expression in Human Breast Cancer MCF7 and Prostate Cancer PC3 Cells by the Human Copper-Binding Peptide GHK-Cu.
}

\author{
Loren Pickart, Anna Margolina *
}

Skin Biology, 4122 Factoria Boulevard SE, Suite Number 200, Bellevue, WA, 98006, USA; E-Mails: drlorenpickart@gmail.com; anna@amargolina.com

* Correspondence: Anna Margolina; E-Mail: anna@amargolina.com

Academic Editor: Lunawati L. Bennett

Special Issue: Cancer Genetics and Epigenetics Alterations

OBM Genetics

2021, volume 5, issue 2

doi:10.21926/obm.genet. 2102128
Received: January 20, 2021

Accepted: March 25, 2021

Published: April 06, 2021

\begin{abstract}
The human copper-binding peptide GHK-Cu is a naturally occurring small plasma tripeptide (glycyl-I-histidyl-I-lysine) with a high affinity for copper (2+). GHK-Cu has multiple biological effects. It is known to stimulate regeneration of skin, nervous tissue, bones, lungs and liver, protect liver from oxidative damage, restore activity of irradiated fibroblasts, reduce inflammation and increase levels of antioxidant enzymes. Recent studies established that GHK modulates activity of a number of genes. It has been shown to reverse pathological expression of $70 \%$ genes in a gene signature for metastasis-prone colon cancer and shift gene expression in COPD lungs from destruction to healthy remodeling. In this paper, we present GHK-Cu's gene effects on MCF7 breast cancer cells and PC3 prostate cancer cells and review laboratory evidence supporting GHK's ability to restore tissue integrity and health via multiple mechanisms, which can be beneficial for cancer treatment.
\end{abstract}

\section{Keywords}

GHK-Cu; copper peptides; breast cancer; prostate cancer; gene profiling; epigenetic modifications; metastasis; anti-inflammatory; caspase

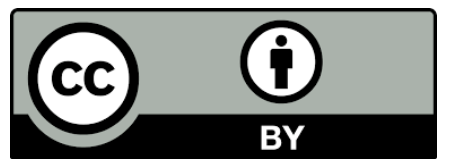

(C) 2021 by the author. This is an open access article distributed under the conditions of the Creative Commons by Attribution License, which permits unrestricted use, distribution, and reproduction in any medium or format, provided the original work is correctly cited. 


\section{Introduction}

A naturally occurring copper-binding peptide GHK (Glycyl-L-Histidyl-L-Lysine) was discovered in human plasma albumin fraction in 1973 by Pickart. GHK has high affinity for copper and usually exists as its copper-complex GHK-Cu (Figure 1).

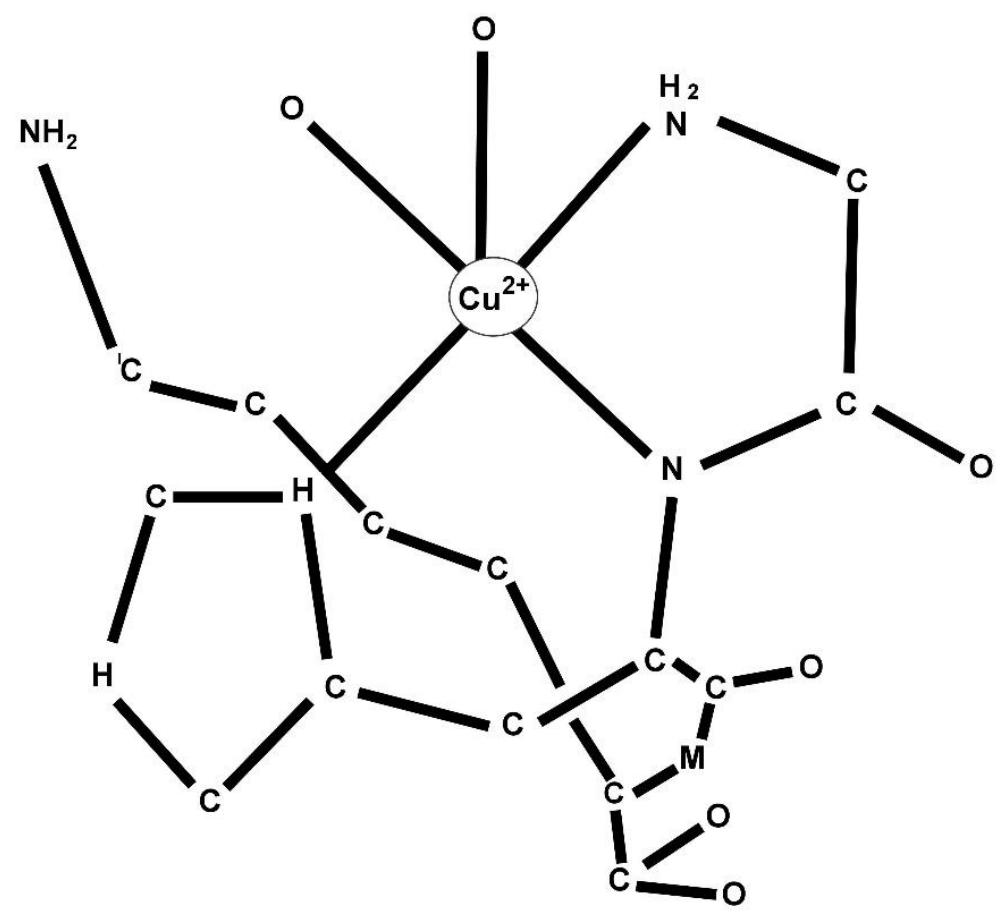

Figure 1 Chemical structure of GHK-Cu.

In a 1973 study, that led to discovery of GHK, plasma from young individuals, which was added to liver tissue obtained from older individuals, caused old liver tissue to produce proteins more characteristic of younger individuals. It was also established that GHK declines with age. In blood plasma of male medical students at the University of California in San Francisco (average age 25), GHK was measured 200 nanograms per milliliter while in blood plasma of the male medical school faculty at the same University (average age 60) GHK was measured 80 nanograms per milliliter [1]. These two facts, GHK being able to shift protein synthesis in old liver tissue to a much younger state and the fact that GHK declines with age, could not be adequately explained, until recent research discovered that GHK is able to affect expression of multiple human genes, generally shifting gene expression to a healthier state.

In 2010, Hong at al. demonstrated that GHK can reverse gene expression characteristic for a gene expression signature for early stage "metastasis prone" colon cancers. They used the Broad Institute gene Connectivity Map (cMAP), which is a publicly available repository of gene expression, to find molecules which reverse gene expression characteristic for this signature, proposing that such agents could be used in therapy on early stages of cancer. Out of 1,309 bioactive molecules, GHK and another wound healing agent, securinine, demonstrated the best ability to reverse expression of 54 gene (74 probe set) overexpressed in malignant invasive metastatic colon cancer. The authors 
noted that among genes affected by GHK were node molecules YWHAB, MAP3K5, LMNA, APP, GNAQ, F3, NFATC2, and TGM2, which are involved in regulation of complex molecular networks associated with cancer progression and metastasis. The authors suggested that GHK's and securinine's ability to promote wound-healing, macrophage activation and extracellular matrix remodeling may indicate that these pathways are important in cancer progression and that GHK may be useful in cancer therapy [2].

In 2012, Campbell et al. identified a gene expression signature characteristic for COPD (Chronic Obstructive Lung Disease) and demonstrated that GHK produced favorable changes in gene expression in COPD lung tissues. They also conducted laboratory experiments, confirming that GHK, added to fibroblasts derived from COPD lung tissue, helped restore organization of the actin cytoskeleton, elevated the expression of integrin $\beta 1$, collagen I contraction and remodeling by fibroblasts [3]. In this study, it was confirmed that the Broad Institute Connectivity Map is a reliable tool allowing prediction of biological actions of various compounds. It was confirmed that beneficial gene effects of GHK, discovered through the computer-based tool The Connectivity Map, correlate with its effects in vitro. It was concluded that the Connectivity Map can be used to identify future therapeutics [4].

GHK has been long established as a natural regulator of tissue remodeling, however, until the recent gene expression studies, it was unclear what allows it to exhibit all these diverse positive effects. In 1988, Maquart et al. from Université de Reims Champagne-Ardenne (France) found that GHK at concentrations of $10^{-12}$ and $10^{-11} \mathrm{M}$, maximized at $10^{-9} \mathrm{M}$ was able to stimulate the synthesis of collagen in fibroblasts. The authors noted that GHK sequence is present in the alpha $2(\mathrm{I})$ chain of type I collagen. They proposed a mechanism by which skin stimulates its own repair through a release of small regulatory peptides, which they called matrikines. When skin is wounded, proteolytic enzymes break down collagen in the intercellular matrix, releasing GHK and possibly other biologically active regulators of repair into the site of an injury [5]. In 1992, Maquart et al. established that GHK injected into rat wounds increased an accumulation of collagen and glycosaminoglycans as well as increased DNA synthesis [6]. In 1999, Maquart and co-authors demonstrated for the first time that GHK-Cu regulated skin remodeling process in rats by modulating activity of different metalloproteinases - enzymes that facilitate breakdown of proteins of extracellular matrix [7]. Next, it was shown that GHK not only modulates activity of different matrix metalloproteinases, but also stimulates anti-proteases, maintaining balance between matrix breakdown and synthesis [8].

It's been established in a number of studies that GHK accelerates wound healing, helps restore normal tissue architecture through regulation of tissue remodeling, reduces inflammation and improves antioxidant defense [9]. Because of its long safety record, and its ability to restore healthy tissue architecture, GHK has been widely used in anti-aging skin care products [10]. It has been demonstrated that GHK in skin care products helps reduce wrinkles [11]. GHK incorporated into collagen matrix improved wound healing in rats, stimulating wound contraction and increasing expression of antioxidant enzymes [12]. GHK improved healing of diabetic and ischemic wounds [13$15]$.

In 2012, Matalka et al. proposed that because GHK stimulates the level of p63, a member of the antitumor suppressor family, which includes p53 and p73, it may induce apoptosis in neuroblastoma cells. They tested this hypothesis using SH-SY5Y neuroblastoma cells and confirmed that GHK induces programmed cell death in these cells [16]. GHK has been shown to upregulate expression 
of growth factors during nerve regeneration [17]. It also has been shown to accelerate healing of bone fractures [18]. GHK-Cu and its copper-free form GHK has been shown to upregulate integrin and p63 expression in human cultured keratinocytes restoring their stemness [19]. In our previous papers, we investigated effects of GHK on gene expression relevant to stem cells and brain health as well as general health-positive trends in GHK effects on gene expression [20-22].

In the present paper, we used the Broad Institute's Connectivity Map to investigate effects of GHK in human breast cancer MCF7 cells and prostate PC3 cancer cells. Together with available data on biological effects of GHK, the gene expression data widen our understanding of biological effects of GHK and its possible role in cancer therapy as a therapeutical agent promoting beneficial tissue remodeling and shifting gene expression toward a generally more balanced and healthier state.

\section{Methods}

We used two methods to determine GHK's effect on gene expression. The first is based on Gene Ontology which assigns gene function and diseases. However, this limits results since there are over 100 human cancers and not all are in Gene Ontology. We also did a manual search of all genes affected by GHK.

The Gene Ontology methodology used in this research has been described in the authors' previous publications [21, 22].

The authors used the Broad Institute's Connectivity Map (CMap) - a publicly available computerbased gene profiling tool. The Connectivity Map is a database that contains more than 7,000 gene expression profiles of 5 human cell lines treated with 1,309 distinct small molecules.

The GHK profiles, contained in this repository, are based on PC3 human prostate cancer cells and MCF7 human breast cancer cells. In order to analyze the gene data obtained from the CMap, we used GenePattern - a publicly available computational biology open-source software package developed for the analysis of genomic data. The CEL files were processed with MAS5 and background correction. Files were then uploaded to the ComparativeMarkerSelectionViewer module in order to view fold changes for each probe set. The Gene Ontology descriptions of the molecular function, biological process, and cellular component of gene products were used to obtain GHK induced gene expression results. The gene expression data is given as fold-changes converted into percentage changes.

The authors also used the Broad Institute Chembank - a database which compares biological molecules to non-biological bioactive molecules in terms of similarity of effects on m-RNA production.

\section{Results and Discussion}

\subsection{The Gene Expression Data}

GHK upregulates expression of caspases, such as CASP1, 3, 6,7 8 and 10 (Table 1). Activation of caspases is an essential step in programmed cell death, which helps eliminate damaged and aberrant cells. Impaired apoptosis regulation is one of the early gene expression changes associated with cancer. Inhibition of CASP 10 by MicroRNA-421 is associated with cancer progression [23] Expression of Casp 3 and PTEN was examined in breast cancer patients. Loss of expression of PTEN was higher in breast cancer compared to non-cancerous growth [24] 
Table $1 \mathrm{GHK}$ and gene expression in apoptosis proteins in human breast cancer MCF7 cells and prostate PC3 cells.

\begin{tabular}{lll}
\hline Genes & $\begin{array}{l}\text { Percent Change } \\
\text { Gene Expression }\end{array}$
\end{tabular}

\section{MCF7 PC3}

CASP $1272 \quad 173 \quad$ A protein which is a member of the cysteine-aspartic acid protease (caspase) family. Sequential activation of caspases plays a central role in the execution-phase of cell apoptosis.
CASP $319 \quad 79$ A cysteine-aspartic acid protease that plays a central role in the execution-phase of cell apoptosis. Sequential activation of caspases plays a central role in the execution-phase of cell apoptosis.

\begin{tabular}{|c|c|c|c|}
\hline CASP 6 & 62 & 21 & $\begin{array}{l}\text { A member of the cysteine-aspartic acid protease (caspase) family } \\
\text { of enzymes. Sequential activation of caspases plays a central role } \\
\text { in the execution-phase of cell apoptosis. }\end{array}$ \\
\hline CASP 7 & 93 & 10 & $\begin{array}{l}\text { Sequential activation of caspases plays a central role in the } \\
\text { execution-phase of cell apoptosis. }\end{array}$ \\
\hline CASP8 & NS & 501 & $\begin{array}{l}\text { A member of the cysteine-aspartic acid protease (caspase) family. } \\
\text { Sequential activation of caspases plays a central role in the } \\
\text { execution-phase of cell apoptosis. }\end{array}$ \\
\hline CASP 10 & 1781 & 195 & $\begin{array}{l}\text { A member of the cysteine-aspartic acid protease (caspase) family. } \\
\text { Sequential activation of caspases plays a central role in the } \\
\text { execution-phase of cell apoptosis. }\end{array}$ \\
\hline NLRP1 & 433 & 249 & $\begin{array}{l}\text { Ced-family members contain a caspase recruitment domain } \\
\text { (CARD) and are known to be key mediators of programmed cell } \\
\text { death. }\end{array}$ \\
\hline CARD10 & 146 & 107 & $\begin{array}{l}\text { The caspase recruitment domain participates in apoptosis } \\
\text { signaling. }\end{array}$ \\
\hline
\end{tabular}

NS = Not Significant.

A number of tumor suppressor proteins are upregulated by GHK, including C13orf18, CDKN1C, PWR, PTEN, ING4 and BRCA1. For the growth/cancer inhibitors in Table 2, the most stimulated genes are USP29 (Ubiquitin specific peptidase 29, which was found to have a stabilizing effect on P53) [25], IFNA21 (interferon alpha 21), TP-73 (p73 tumor protein - a member of the p53 transcriptional factors gene family, involved in stress response), LEFTY2 (left-right determination factor 2 - its overexpression in breast cancer restrains tumor growth) [26], IL25 (interleukin 25 - a cytokine, which induces apoptosis in tumor cells) [27]. 
Table 2 GHK and gene expression in cancer suppressors in MCF7 and PC3 cells.

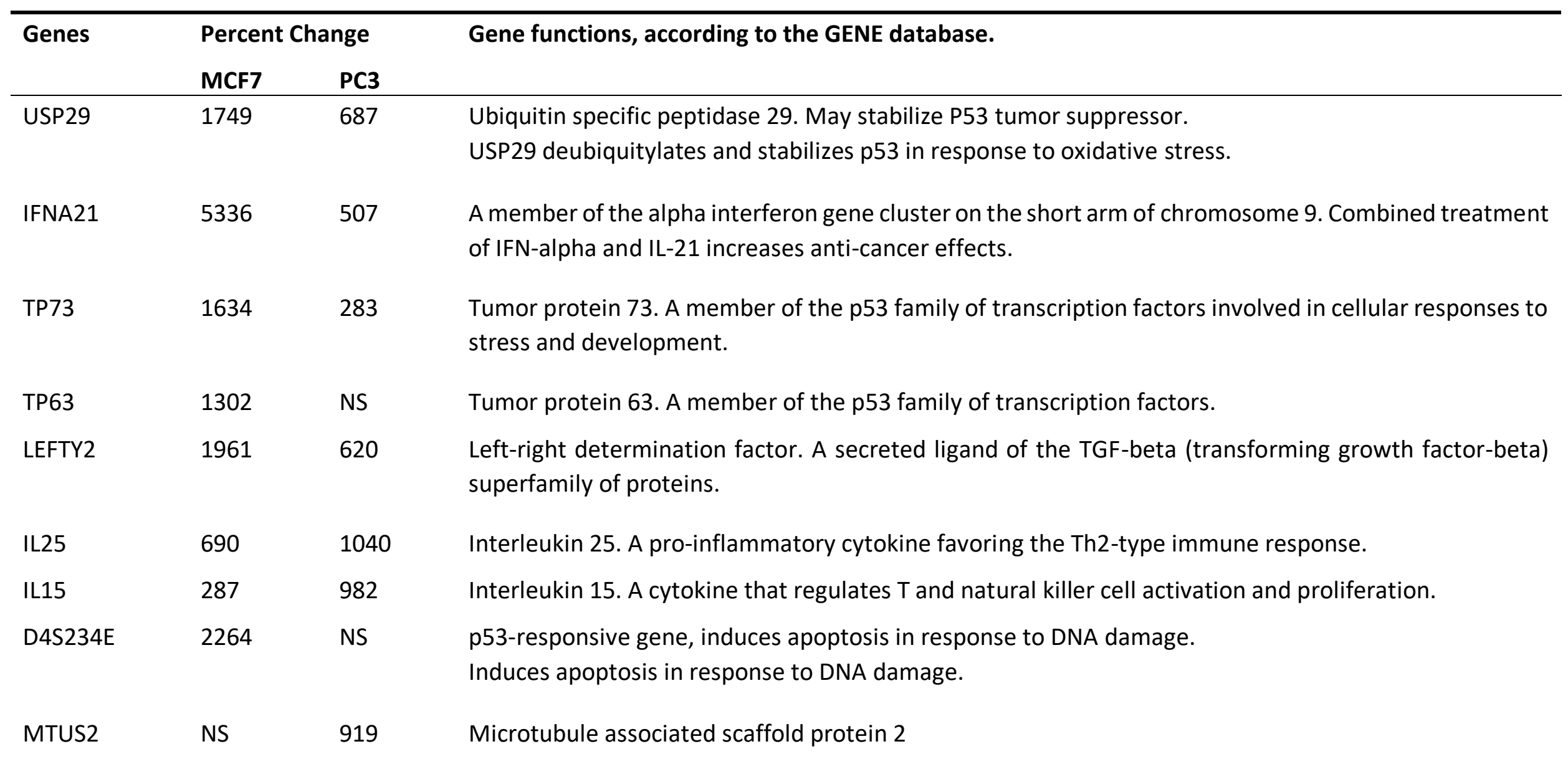


C13 of 18

327

478

CTNNA1

CDKN1C

196

NS

PAWR

APC
A cysteine-rich protein that contains a putative zinc-RING and/or ribbon domain. The encoded protein is related to Run domain Beclin-1-interacting and cysteine-rich domain-containing protein, which plays a role in endocytic trafficking and autophagy. In cervical cancer cell lines, this gene is expressed at low levels and may function as a tumor suppressor.

A member of the inhibitor of growth (ING) family. Members of the ING family associate with and modulate the activity of histone acetyltransferase (HAT) and histone deacetylase (HDAC) complexes and function in DNA repair and apoptosis.

A member of the catenin family of proteins that play an important role in cell adhesion process by connecting cadherins located on the plasma membrane to the actin filaments inside the cell.

Cyclin dependent kinase inhibitor 1C. Mutations in this gene are implicated in sporadic cancers and Beckwith-Wiedemann syndrome, suggesting that this gene is a tumor suppressor candidate.

A tumor suppressor protein that selectively induces apoptosis in cancer cells through intracellular and extracellular mechanisms.

A tumor suppressor protein that acts as an antagonist of the Wnt signaling pathway.

A tumor suppressor that is mutated in a large number of cancers at high frequency.

A negative regulator of the ras signal transduction pathway.

The protein encoded by this gene belongs to the PI3/PI4-kinase family. This protein is an important cell cycle checkpoint kinase that phosphorylates; thus, it functions as a regulator of a wide variety of downstream proteins, including tumor suppressor proteins $\mathrm{p} 53$ and BRCA1, checkpoint kinase CHK2, checkpoint proteins RAD17 and RAD9, and DNA repair protein NBS1.

A tumor suppressor protein that contains a PHD-finger, which is a common motif in proteins involved in chromatin remodeling. 
DCN

207

NS

NS

BRCA1

NRG1
120

127
Decorin. This protein plays a role in collagen fibril assembly. Binding of this protein to multiple cell surface receptors mediates its role in tumor suppression, including a stimulatory effect on autophagy and inflammation and an inhibitory effect on angiogenesis and tumorigenesis.

A 190 kD nuclear phosphoprotein that plays a role in maintaining genomic stability, and it also acts as a tumor suppressor.

Mediates cell-cell signaling and plays critical role in the growth and development of multiple organ systems. Dysregulation of the gene is linked to cancer, schizophrenia, and bipolar disorder. 
An analysis of the GENE database descriptions shows that GHK upregulates a number of tumor suppressor proteins, including those which together with other tumor suppressors, DNA damage sensors, and signal transducers are part of a larger protein complex - the BRCA1-associated genome surveillance complex (BASC).

One particularly important gene upregulated by GHK is ATM, which as stated in the GENE database, "is an important cell cycle checkpoint kinase that phosphorylates; thus, it functions as a regulator of a wide variety of downstream proteins, including tumor suppressor proteins p53 and BRCA1, checkpoint kinase CHK2, checkpoint proteins RAD17 and RAD9, and DNA repair protein NBS1. This protein and the closely related kinase ATR are thought to be master controllers of cell cycle checkpoint signaling pathways that are required for cell response to DNA damage and for genome stability." GHK stimulates RNA production of ATM $80 \%$ for breast cancer cells and $120 \%$ for prostate cells.

We also found strong suppression of genes involved in drug resistance in cancer cells, suppression of apoptosis, inflammation and cell proliferation (Table 3).

Table 3 GHK downregulates gene expression in cancer enhancers in MCF7 and PC3 cells.

\begin{tabular}{|c|c|c|c|}
\hline ABCB1 & -900 & -2451 & $\begin{array}{l}\text { A member of the superfamily of ATP-binding cassette (ABC) } \\
\text { transporters. Creates drug resistance in ovarian cancer and breast } \\
\text { cancer cell lines. }\end{array}$ \\
\hline STAT5A & -4077 & -359 & $\begin{array}{l}\text { Activation of this protein in myeloma and lymphoma associated } \\
\text { with a TEL/JAK2 gene fusion is independent of cell stimulus and has } \\
\text { been shown to be essential for tumorigenesis. }\end{array}$ \\
\hline IGF1 & NS & -864 & $\begin{array}{l}\text { A natural human growth hormone during childhood but can } \\
\text { promote abnormal growth and invasion of cancer, especially of the } \\
\text { prostate and breast. It may also help cancer cell lines to divide and } \\
\text { grow blood vessels. }\end{array}$ \\
\hline FGFR2 & -243 & -235 & $\begin{array}{l}\text { FGFR2 inhibitors reduce some cancers. Has important roles in } \\
\text { embryonic development and tissue repair, especially bone and } \\
\text { blood vessels. On a molecular level, these signals mediate cell } \\
\text { division, growth and differentiation. When the gene is targeted by } \\
\text { drugs in gastric tumors, it is effective. Mutations of the gene are a } \\
\text { risk factor for breast cancer. }\end{array}$ \\
\hline FAIM2 & -590 & -462 & $\begin{array}{l}\text { Anti-apoptotic protein which protects cancer cells from Fas- } \\
\text { induced apoptosis. Associated with breast cancer, neuroblastoma, } \\
\text { and small cell lung cancer. }\end{array}$ \\
\hline TNF & 124 & -153 & $\begin{array}{l}\text { Stimulates cancer cells' growth, proliferation, invasion, and } \\
\text { metastasis, and tumor angiogenesis. }\end{array}$ \\
\hline
\end{tabular}

Table 4 is the comparison of GHK effect on m-RNA production with bioactive synthetic molecules using the Broad Institutes Chem Bank. The two most similar molecules to GHK were STOCK1N-35874, 
a potential therapeutic drug for the treatment of metastatic prostate carcinoma ( $88 \%$ similarity), and 6-bromoindirubin-3'-oxime - a drug which supports stem cells and inhibits metastatic cancer (68\% similarity).

Table 4 Chem bank table. Non-biological molecules similar to gly-his-lys in terms of $\mathrm{m}$ RNA production.

\begin{tabular}{|c|c|c|c|c|c|}
\hline Rank & CMap Name & Dose & Cells & Score & \\
\hline 1 & Gly-His-Lys & $1 \mathrm{uM}$ & PC3 & 1 & \\
\hline 2 & STOCK1N-35874 & $14 \mathrm{uM}$ & PC3 & 0.88 & $\begin{array}{l}\text { Potential therapeutic drug for the } \\
\text { treatment of metastatic prostate } \\
\text { carcinoma }\end{array}$ \\
\hline 3 & $\begin{array}{l}\text { 6- } \\
\text { bromoindirubin- } \\
\text { 3-oxime }\end{array}$ & $500 \mathrm{nM}$ & PC3 & 0.68 & $\begin{array}{l}\text { Supports stem cells, inhibits metastatic } \\
\text { cancer }\end{array}$ \\
\hline 4 & tiletamine & 15 uM & PC3 & 0.51 & Injectable anesthetic \\
\hline 5 & cefalexin & $11 \mathrm{uM}$ & MCF7 & 0.5 & $\begin{array}{l}\text { Antibiotic for a number of bacterial } \\
\text { infections }\end{array}$ \\
\hline 6 & minoxidil & 19 uM & PC3 & 0.49 & $\begin{array}{l}\text { Antihypertensive vasodilator used to treat } \\
\text { hair loss }\end{array}$ \\
\hline 7 & Prestwick-857 & $12 \mathrm{uM}$ & MCF7 & 0.49 & $\begin{array}{l}\text { Antiprotozoal agent effective in } \\
\text { trypanosomiasis, leishmaniasis, and some } \\
\text { fungal infections }\end{array}$ \\
\hline 8 & citiolone & 25 uM & MCF7 & .485 & $\begin{array}{l}\text { A drug used in liver therapy, free radical } \\
\text { scavenger }\end{array}$ \\
\hline 9 & nystatin & $4 \mathrm{uM}$ & PC3 & 0.47 & An antifungal medication \\
\hline 10 & bambuterol & $10 \mathrm{uM}$ & MCF7 & 0.47 & $\begin{array}{l}\beta \text { adrenoceptor agonist used in the } \\
\text { treatment of asthma }\end{array}$ \\
\hline
\end{tabular}

Even though the Broad Institute gene data indicate that GHK upregulates a number of gene encoding caspases and other proteins, which are commonly considered to be tumor suppressors, while downregulating a number of genes, which are commonly considered to be tumor enhancing genes, by itself gene data would not be enough to draw a conclusion that GHK may be developed into a future anti-cancer therapeutics. However, taken together with evidence obtained by other researchers, such as Hong et al. who established that GHK reverses unfavorable expression of a number of node molecules whose expression is altered in metastasis-prone colon cancer, it warrants future investigation. Since its discovery in 1973, GHK has been investigated for its beneficial role in wound healing and tissue remodeling. Taken together with gene data, existing laboratory data supports GHK's ability to restore normal tissue architecture through remodeling, repair DNA after 
irradiation, reducing inflammation and oxidative damage. Thus, laboratory data compliments gene data, supporting health-positive effects of GHK.

\subsection{Biological Effects of GHK-Cu Which Support Its Beneficial Effects on Tissue Integrity and Health}

It has been suggested by Peled et al. that copper-free GHK promotes the survival of stem cells and possibly the de-differentiation of cells, while GHK with copper 2+ promotes cell differentiation [28].

GHK has strong anti-inflammatory and anti-oxidant effects. Inflammation is now considered a key factor in tumor progression. Chronic inflammation from incomplete wound healing has been shown to be causative in many cancers [29]. GHK suppressed TNF-alpha dependent IL-6 secretion in human dermal fibroblasts and inhibited bleomycin-induced pulmonary fibrosis in mice by suppressing TGFbeta [30].

GHK quenches toxic by-products of lipid peroxidations, protecting cells from oxidative damage [31, 32]. GHK also protects cells from oxidative damage by blocking iron release from ferritin [33]. GHK in Caco-2 cells reduced levels of reactive oxygen species hydroxyl (.OH) and peroxyl (ROO.) radical and was more effective than two other antioxidative endogenous peptides, carnosine and reduced glutathione [34].

GHK-Cu may have DNA-repair actions as evidenced from a study, which showed that GHK-Cu at 1 nanomolar was able to restore normal function in cultured human fibroblasts exposed to radioactive treatment $(5000 \mathrm{rad})$. The irradiated fibroblasts treated with GHK showed much faster growth, similar to the normal (non-irradiated control cells). In addition, GHK-treated irradiated fibroblasts showed increased production of important growth factors [35].

In early wound healing experiments, GHK was found to stimulate production of a small, leucinerich proteoglycan, decorin. It was observed that decorin mRNA levels kept increasing in the rat wounds until day 22 - the end of the experiment. GHK-Cu also stimulated the level of decorin in dermal fibroblast cultures [36]. Recent studies highlight an important role of decorin as a "guardian from the matrix", which has multiple anti-tumorigenic properties. Decorin binds and down-regulates selected tyrosine kinases, overexpressed in cancer cells. Through molecules which decorin controls, such as growth factors, decorin suppresses tumor cell proliferation, survival, migration, and angiogenesis [37].

Support for evidence of GHK-Cu's anti-cancer actions also comes from two studies on mice implanted with mouse cancers. This includes a 1983 paper by Linus Pauling and colleagues on the inhibition of Ehrlich ascites tumors in mice and our 2014 paper on the inhibition of sarcoma-180 tumors in mice. In Pauling's study, mice were treated with copper peptide GGH-Cu, which is very similar to GHK-Cu, plus ascorbic acid. As a result, $40 \%$ of the mice that received GGH-Cu plus ascorbic acid survived beyond 60 days and rejected new tumor implants, while all control mice died within 30 days [38].

In our study, we followed Pauling's protocol, but used a solid tumor - 180 mouse sarcoma. The mixture of GHK-Copper 2+ and ascorbic acid produced a 60\% reduction in tumor growth [39]. Our approach to using GHK and other small copper peptides as an anti-cancer treatment is described in our 2017 patent [40]. 


\subsection{GHK vs. GHK-Cu}

Both copper-free GHK and GHK-Cu have been reported to induce various effects. However, given GHK's very high affinity for copper $2+$, it is likely that GHK primarily exists as GHK-Cu in most cell and tissue cultures. The Broad culture medium contained 3.16 micromolar copper $2+$ to which was added $5 \%$ serum with that contained 1.6 micromolar exchangeable copper $2+$ in its albumin protein. So, the final culture medium had about 3.08 micromolar exchangeable copper $2+$ or about twice the level in human serum.

Thus, we cannot exclude the possibility that the GHK tested in the Broad's tests was actually GHK$\mathrm{Cu}$. In addition, the copper chelator bathocuproine had always stopped GHK's effects in our cell culture tests.

\subsection{Possible Mechanisms Explaining Biological Effects of GHK}

Since its discovery in 1973, GHK has been shown to exhibit a wide array of beneficial biological actions. Since free copper is very toxic to marine organisms, copper binding peptides as regulatory molecules appear very early in the course of evolution. In the Caribbean spiny lobster Panulirus argus, GHK stimulates synchronized release (pumping) of larvae from eggs [41] It also aids in settlement and metamorphosis of the larvae of barnacle Balanus amphitrite Darwin [42]. Since small di- and tri-peptides were the first to evolve, long before larger and more complex proteins, it makes sense that in the course of evolution, various small peptides became associated with DNA, controlling gene activity for optimum survival of the organism. Small peptides, which gave an organism the best advantage, were preserved and eventually included into more complex regulatory systems.

In the past, most proposed theories on how GHK works were focused on its ability to bind copper. GHK is a small peptide with molecular weight $403.92 \mathrm{~g} / \mathrm{mol}$. This small size allows $\mathrm{GHK}$ to approach cell membrane receptors more easily than large proteins. lonic copper is tightly controlled in the body and transported between tissues by the plasma protein albumin. GHK's affinity for copper ( $p K$ binding 16.4) is 10 million times higher than other tripeptides and is almost equivalent to albumin's (pK binding 16.2). GHK can easily obtain copper 2+ from albumin. GHK is released from extracellular matrix proteins, such as SPARC and collagen during proteolytic tissue breakdown in case of an injury. Thus, GHK generated in tissues after an injury may allow-for quick distribution of safe and biologically available copper within the tissue [43].

However, over the past 10 years, advanced gene profiling studies created a need to revisit mechanisms of GHK actions. GHK seems to be able to interact with cell receptors, activating multiple biochemical pathways [44]. GHK has been shown to protect liver from oxidative damage, and this effect cannot be easily explained through GHK's ability to modulate copper metabolism [45].

A recent research study compared the effects of oxidized alginate hydrogel (alginate di-aldehyde; $A D A$ ) with or without GHK and ADA with crosslinked gelatin with and without GHK on umbilical osteogenic cell culture. Cell viability and proliferation in GHK-containing materials was significantly higher than in ADA and ADA- gelatin gels without GHK. The authors noted that ADA-GHK gel had 10fold increase in Runx 2 mRNA levels even before their osteogenesis was chemically induced. The authors found out that the effects of GHK on osteoblasts was mediated by activation of ILK-integrin linked kinase. They proposed that GHK binds to ILK on cell membranes, activating ILK-related pathways [46]. 
It is worth noticing that GHK-Cu can bind to the DNA molecule, forming copper-complexes. Thus, it is possible that it can regulate gene activity directly [47].

However, this still doesn't explain GHK's effect on multiple human genes and doesn't answer the question of why all documented effects of GHK-Cu are health-positive. Most likely the comprehensive mechanism of GHK's effects will be developed on the crossroads of its copperbinding properties and its ability to bind to cellular receptors and DNA, triggering various biological responses.

\subsection{Safety and Possible Dosages of Copper Peptides}

In our studies, the LD50 (median lethal dose in 50\% of mice) for GHK-Cu was 8 mgs per $25 \mathrm{~g}$ mice for GHK-Cu. Extrapolated to human weight, this would be $320 \mathrm{mg} / \mathrm{kg}$ or $22,400 \mathrm{mg}$ in a $70 \mathrm{~kg}$ human. The injection of 0.065 milligrams GHK-Cu in a $25 \mathrm{~g}$ mouse would correspond to $182 \mathrm{mg}$ in a $70 \mathrm{~kg}$ human, suggesting a wide margin of safety.

In the Hong et al. study [2], GHK produced suppression of many cancer metastasis genes at 1 micromolar. If this level was used as in the experiments above, the mice would have been injected with $0.2 \mathrm{ml}$ of liquid containing 0.68 nanograms of GHK. In the Maquart et al. study, GHK-Cu increased fibroblast production of decorin by $302 \%$ at 1 nanomolar [34].

\section{Conclusion}

GHK, a naturally occurring copper peptide, which declines with age, upregulates a number of cancer suppressors and downregulates a number of genes associated with cancer progression. As Hong et al. study indicates, GHK reverses expression of genes associated with early stages of aggressive metastatic colon cancer. It modulates gene expression in tissues derived from COPD lungs, switching gene expression to more regeneration, more restructuring and less inflammation. GHK improves wound healing, balances breakdown and synthesis of collagen, and accelerates repair of skin, bones and stomach lining. It possesses anti-oxidant and anti-inflammatory properties and protects the liver from toxins. As a regulatory molecule which appeared very early in evolution, GHK may hold the key to health and wellness through multiple mechanisms, which include regulating copper, activating pathways linked to repair and regeneration as well as acting directly on DNA, modulating gene expression.

It is possible that the sharp reduction in GHK-Cu during normal aging reduces the expression of protective anti-cancer genes and increases risk of cancer. The uniqueness of GHK is that it may allow simultaneous resetting of multiple genes to target an array of various biochemical pathways to increase resistance to cancer and reverse pathological epigenetic changes in cancerous cells. Unlike many other potential therapeutic agents discovered through gene profiling, GHK has a wealth of laboratory data, supporting its ability to protect and repair tissues.

While cancer causes and treatments are very complex, it is possible that GHK-Cu, which has multiple effects on gene expression and has been shown to exhibit favorable gene effects reversing gene expression back to health in metastasis prone colon cancer gene signature and COPPD gene signature, can help slow or regress selected cancers in humans.

GHK has an excellent safety record and a long history of use in skin care. GHK can be administered intravenously, orally (in liposomal form [48]) or applied to skin. GHK and its copper complexes penetrate the stratum corneum and can be delivered transdermally in creams, gels or skin patches 
$[49,50]$. Considering GHK's potential in having generalized health-positive gene effects which have been confirmed to encourage tissue remodeling and wound healing, its gene effects in breast cancer and prostate cancer cells have to be further investigated for possible practical application in anticancer therapy.

\section{Acknowledgment}

Authors want to thank Cassia McClain for her invaluable help in preparing the manuscript and Jessica Michelle Vasquez-Soltero for processing the gene profiling data.

\section{Author Contributions}

Pickart L. designed and performed the research and computations. Pickart L. and Margolina A. analysed data, conceptualized and organized the manuscript. Pickart L. and Margolina A. equally contributed to writing the manuscript, editing, proofreading and verifying the material.

\section{Competing Interests}

The authors have declared that no competing interests exist.

\section{References}

1. Pickart LR. A tripeptide from human serum which enhances the growth of neoplastic hepatocytes and the survival of normal hepatocytes. San Francisco, CA: University of California; 1973.

2. Hong Y, Downey T, Eu KW, Koh PK, Cheah PY. A 'metastasis-prone' signature for early-stage mismatch-repair proficient sporadic colorectal cancer patients and its implications for possible therapeutics. Clin Exp Metastasis. 2010; 27: 83-90.

3. Campbell JD, McDonough JE, Zeskind JE, Hackett TL, Pechkovsky DV, Brandsma CA, et al. A gene expression signature of emphysema-related lung destruction and its reversal by the tripeptide GHK. Genome Med. 2012; 4: 67.

4. Meiners $\mathrm{S}$, Eickelberg $\mathrm{O}$. Next-generation personalized drug discovery: The tripeptide GHK hits center stage in chronic obstructive pulmonary disease. Genome Med. 2012; 4: 70.

5. Maquart FX, Pickart L, Laurent M, Gillery P, Monboisse JC, Borel JP. Stimulation of collagen synthesis in fibroblast cultures by the tripeptide-copper complex glycyl-L-histidyl-L-lysine-Cu². FEBS Lett. 1988; 238: 343-346.

6. Wegrowski Y, Maquart FX, Borel JP. Stimulation of sulfated glycosaminoglycan synthesis by the tripeptide-copper complex glycyl-L-histidyl-L-lysine-Cu²+. Life Sci. 1992; 51: 1049-1056.

7. Siméon A, Monier F, Emonard H, Gillery P, Hornebeck W, Maquart FX, et al. Expression and activation of matrix metalloproteinases in wounds: Modulation by the tripeptide-copper complex glycyl-L-histidyl-L-lysine-Cu²+. J Invest Dermatol. 1999; 112: 957-964.

8. Siméon A, Emonard H, Hornebeck W, Maquart FX. The tripeptide-copper complex glycyl-L-histidyl-L-lysine-Cu ${ }^{2+}$ stimulates matrix metalloproteinase-2 expression by fibroblast cultures. Life Sci. 2000; 67: 2257-2265.

9. Pickart L, Margolina A. Skin regenerative and anti-cancer actions of copper peptides. Cosmetics. 2018; 5: 29.

10. Pickart L. The human tri-peptide GHK and tissue remodeling. J Biomater Sci Polym Ed. 2008; 19 : 
969-988.

11. Pickart L, Margolina A. Anti-aging activity of the GHK peptide-the skin and beyond. J Aging Res Clin Pract. 2012; 1: 13-15.

12. Arul V, Gopinath D, Gomathi K, Jayakumar R. Biotinylated GHK peptide incorporated collagenous matrix: A novel biomaterial for dermal wound healing in rats. J Biomed Mater Res Part B Appl Biomater. 2005; 73: 383-391.

13. Arul V, Kartha R, Jayakumar R. A therapeutic approach for diabetic wound healing using biotinylated GHK incorporated collagen matrices. Life Sci. 2007; 80: 275-284.

14. Gul NY, Topal A, Cangul IT, Yanik K. The effects of topical tripeptide copper complex and heliumneon laser on wound healing in rabbits. Vet Dermatol. 2008; 19: 7-14.

15. Canapp Jr SO, Farese JP, Schultz GS, Gowda S, Ishak AM, Swaim SF, et al. The effect of topical tripeptide-copper complex on healing of ischemic open wounds. Vet Surg. 2003; 32: 515-523.

16. Matalka LE, Ford A, Unlap MT. The tripeptide, GHK, induces programmed cell death in SH-SY5Y neuroblastoma cells. J Biotechnol Biomater. 2012; 2: 1000144.

17. Ahmed MR, Basha SH, Gopinath D, Muthusamy R, Jayakumar R. Initial upregulation of growth factors and inflammatory mediators during nerve regeneration in the presence of cell adhesive peptide-incorporated collagen tubes. J Peripher Nerv Syst. 2005; 10: 17-30.

18. Cherdakov VY, Smakhtin MY, Dubrovin GM, Dudka VT, Bobyntsev II. Synergetic antioxidant and reparative action of thymogen, dalargin and peptide gly-his-lys in tubular bone fractures. Exp Biol Med. 2010; 4: 15-20.

19. Kang YA, Choi HR, Na JI, Huh CH, Kim MJ, Youn SW, et al. Copper-GHK increases integrin expression and p63 positivity by keratinocytes. Arch Dermatol Res. 2009; 301: 301-306.

20. Pickart L, Margolina A. The effect of the human plasma molecule GHK-Cu on stem cell actions and expression of relevant genes. OBM Geriatr. 2018; 2: 1803009.

21. Pickart L, Vasquez-Soltero JM, Margolina A. GHK and DNA: Resetting the human genome to health. BioMed Res Int. 2014; 2014: 151479.

22 Pickart L, Vasquez-Soltero JM, Margolina A. The effect of the human peptide GHK on gene expression relevant to nervous system function and cognitive decline. Brain Sci. 2017; 7: 20.

23. Hu TB, Chen HS, Cao MQ, Guo FD, Cheng XY, Han ZB, et al. MicroRNA-421 inhibits caspase-10 expression and promotes breast cancer progression. Neoplasma. 2018; 65: 49-54.

24. Yang XF, Xin Y, Mao LL. Clinicopathological significance of PTEN and caspase-3 expressions in breast cancer. Chin Med Sci J. 2008; 23: 95-102.

25. Liu J, Chung HJ, Vogt M, Jin Y, Malide D, He L, et al. JTV1 co-activates FBP to induce USP29 transcription and stabilize p53 in response to oxidative stress. EMBO J. 2011; 30: 846-858.

26. Naidu DG, Tang M, Tabibzadeh S. Lefty peptides, derived by MMP2 cleavage, act as a new class of gelatinase A inhibitor. Front Biosci. 2008; 13: 7193-7201.

27. Gelaleti GB, Borin TF, Maschio-Signorini LB, Moschetta MG, Jardim-Perassi BV, Calvinho GB, et al. Efficacy of melatonin, IL-25 and silL-17B in tumorigenesis-associated properties of breast cancer cell lines. Life Sci. 2017; 183: 98-109.

28. Peled T, Fibach E, Treves A. Methods of controlling proliferation and differentiation of stem and progenitor cells. Washington, DC: United States Patent and Trademark Office; 2005; US6962698B1.

29. Coussens LM, Werb Z. Inflammation and cancer. Nature. 2002; 420: 860-867. 
30. Zhou XM, Wang GL, Wang XB, Liu L, Zhang $Q$, Yin Y, et al. GHK peptide inhibits bleomycin-induced pulmonary fibrosis in mice by suppressing TGF $\beta 1 / S m a d-m e d i a t e d$ epithelial-to-mesenchymal transition. Front Pharmacol. 2017; 8: 904.

31. Beretta G, Arlandini E, Artali R, Anton JM, Facino RM. Acrolein sequestering ability of the endogenous tripeptide glycyl-histidyl-lysine (GHK): Characterization of conjugation products by ESI-MSn and theoretical calculations. J Pharm Biomed Anal. 2008; 47: 596-602.

32. Beretta G, Artali R, Regazzoni L, Panigati M, Facino RM. Glycyl-histidyl-lysine (GHK) is a quencher of $\alpha, \beta$-4-hydroxy-trans-2-nonenal: A comparison with carnosine. Insights into the mechanism of reaction by electrospray ionization mass spectrometry, $1 \mathrm{H} N \mathrm{NR}$, and computational techniques. Chem Res Toxicol. 2007; 20: 1309-1314.

33. Miller DM, DeSilva D, Pickart L, Aust SD. Effects of glycyl-histidyl-lysyl chelated Cu (II) on ferritin dependent lipid peroxidation. In Antioxidants in therapy and preventive medicine. Boston, MA: Springer; 1990. pp.79-84.

34. Sakuma S, Ishimura M, Yuba Y, Itoh Y, Fujimoto Y. The peptide glycyl-L-histidyl-L-lysine is an endogenous antioxidant in living organisms, possibly by diminishing hydroxyl and peroxyl radicals. Int J Physiol Pathophysiol Pharmacol. 2018; 10: 132.

35. Pollard JD, Quan S, Kang T, Koch RJ. Effects of copper tripeptide on the growth and expression of growth factors by normal and irradiated fibroblasts. Arch Facial Plast Surg. 2005; 7: 27-31.

36. Siméon A, Wegrowski Y, Bontemps Y, Maquart FX. Expression of glycosaminoglycans and small proteoglycans in wounds: Modulation by the tripeptide-copper complex glycyl-L-histidyl-L-ly-

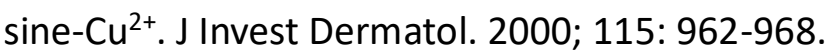

37. Reed CC, Waterhouse A, Kirby S, Kay P, Owens RT, McQuillan DJ, et al. Decorin prevents metastatic spreading of breast cancer. Oncogene. 2005; 24: 1104-1110.

38. Kimoto E, Tanaka H, Gyotoku J, Morishige F, Pauling L. Enhancement of antitumor activity of ascorbate against Ehrlich ascites tumor cells by the copper: Glycylglycylhistidine complex. Cancer Res. 1983; 43: 824-828.

39. Pickart L, Vasquez-Soltero JM, Pickart FD, Majnarich J. GHK, the human skin remodeling peptide, induces anti-cancer expression of numerous caspase, growth regulatory, and DNA repair genes. J Anal Oncol. 2014; 3: 79-87.

40. Pickart L. Non-toxic skin cancer therapy with copper peptides. Washington, DC: United States Patent and Trademark Office; 2017; US9586989B1.

41. Ziegler TA, Forward RB. Larval release behaviors in the Caribbean spiny lobster, Panulirus argus: Role of peptide pheromones. J Chem Ecol. 2007; 33: 1795-1805.

42. Tegtmeyer K, Rittschof D. Synthetic peptide analogs to barnacle settlement pheromone. Peptides. 1988; 9: 1403-1406.

43. Lane TF, Iruela-Arispe ML, Johnson RS, Sage EH. SPARC is a source of copper-binding peptides that stimulate angiogenesis. J Cell Biol. 1994; 125: 929-943.

44. Pickart L, Vasquez-Soltero JM, Margolina A. GHK peptide as a natural modulator of multiple cellular pathways in skin regeneration. BioMed Res Int. 2015; 2015: 648108.

45. Mlu S, Konoplia AI, Sever'ianova LA, Shveĭnov IA. Pharmacological correction of immuno-metabolic disorders with the peptide Gly-His-Lys in hepatic damage induced by tetrachloromethane. Patologicheskaia fiziologiia i eksperimental'naia terapiia. 2003; 2: 19-21.

46. Klontzas ME, Reakasame S, Silva R, Morais JC, Vernardis S, MacFarlane RJ, et al. Oxidized alginate hydrogels with the GHK peptide enhance cord blood mesenchymal stem cell osteogenesis: A 
paradigm for metabolomics-based evaluation of biomaterial design. Acta Biomater. 2019; 88: 224-240.

47. Chikira M, Sato T, Antholine WE, Petering DH. Orientation of non-blue cupric complexes on DNA fibers. J Biol Chem. 1991; 266: 2859-2863.

48. Erdem S. Glycyl-L-histidyl-L-liysine-Cu (2+) loaded liposome formulations. Marmara Pharm J. 2010; 14: 91-97.

49. Hostynek JJ, Dreher F, Maibach HI. Human skin penetration of a copper tripeptide in vitro as a function of skin layer. Inflamm Res. 2011; 60: 79-86.

50. Mazurowska L, Mojski M. ESI-MS study of the mechanism of glycyl-I-histidyl-I-lysine-Cu (II) complex transport through model membrane of stratum corneum. Talanta. 2007; 72: 650-654.

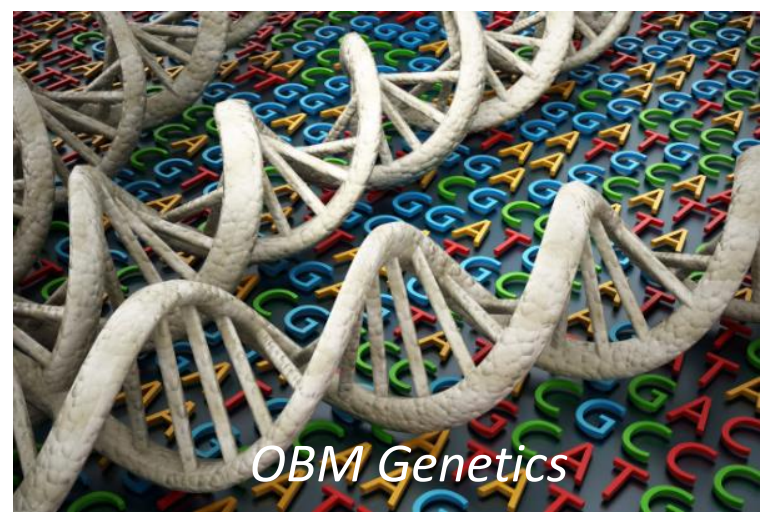

Enjoy OBM Genetics by:

1. Submitting a manuscript

2. Joining in volunteer reviewer bank

3. Joining Editorial Board

4. Guest editing a special issue

For more details, please visit: http://www.lidsen.com/journals/genetics 